\title{
ANALYSIS OF FEEDBACKS OF CHEMISTRY TEXTBOOKS USERS IN POLAND
}

\author{
Iwona Maciejowska \\ Jagiellonian University, Faculty of Chemistry, Krakow, \\ Poland
}

\author{
Malgorzata Krzeczkowska \\ Jagiellonian University, Faculty of Chemistry, Krakow, \\ Poland, VI Liceum Ogolnoksztalcace, Krakow, Poland
}

\begin{abstract}
As a result of restructuring of the education system in Poland in 1999, a number of new textbooks have appeared. Textbook optimization involves familiarization with the feedback of students and teachers regarding the publishers. In the presented research, this method has been used, involving the feedback from the users. The questionnaire for the teachers at the lower and the upper secondary level in various regions of Poland has been prepared. The examinations have shown a need to create detailed standards regulating the suitability of the textbook in the process of teaching-learning.
\end{abstract}

Key words: analysis, questionnaire, chemistry, textbook, teacher.

\section{Introduction}

The analysis of textbooks is a fairly popular subject of didactical testing in the world (Bakonis, 1998; Koulaidis, 2004; Pingel, 1999; Weinbrenner, 1992). Unfortunately, at least in Poland, this type of testing is very poorly developed, which may be due to the low access to foreign language materials describing methodology (with the deficiency of domestic analysis), as well as examples of such tests. The conference presentations dedicated for the subject are very rare and no Polish language paper is available where the results of tests of chemistry didactics may be published, which would allow to use such results by the broader spectrum of Polish teachers without sufficient every day command of the English language. These teachers, at the beginning of every school year, face the following dilemma: which textbook should be selected?

\section{Background}

As a result of the education system restructuring, taking place in 1999 Poland, the market offer of new textbooks is very rich. Currently, the teacher of the lower secondary school may select from 23 textbooks, while the teacher of the upper secondary school (general education) may choose from as many as 15 textbooks, a large contrast compared to the previous years where only 2-3 publications were available.

With respect to the efficiency of the learning process, the methods of developing textbooks for pupils should be sought such that every subsequent book is better and better. At the same time, while creating a new textbook, unconditionally all the textbooks issued to date, supporting teaching the specific subject to the pupils, must be known. Learning from the errors of others, the author is capable of avoiding making his own mistakes. One of the optimization methods involves the familiarization with the feedback of 
the pupils and teachers - as individuals directly using the book - on the publications and publishers functioning on the market to date.

The textbooks may be examined with the use of descriptive analyses and comparative analyses, making references to feedbacks of other users, the so-called competent judges, experimental tests, observations graph and matrix methods (internal order analysis), thesaurus method, etc. (Pilch, 2001; Skrzypczak, 2003). The method of making reference to the feedback of the users has been used in the tests described below.

\section{Purpose of Research}

A purpose of this research was to get opinions formed by teachers with regard to school textbooks - those used at present as well as those they would wish to use in the future. A particular emphasis was placed on the opinions within the scope of substance content, graphics and language used in the examined textbooks. A survey encompassed the following aspects: substance (text layout correctness and logic, relevance of presented information and its compliance with scientific findings), graphics and language (style of responses, criteria of grammatical correctness).

The purpose of the conducted research was to assess chemistry textbooks available on the market and, based on research findings - suggest a universal model of textbook.

Intention of this research was also to diagnose needs of those teachers who use textbooks as their teaching aid during chemistry lessons. Particular emphasis was placed on:

- analysis of teacher self-evaluation with relation to their work with textbooks during lessons, as well as to their actual application,

- acquaintance with teacher opinions paying a special attention to independent work with the textbooks,

- knowledge of textbook selection preferences and teacher expectations.

\section{Methodology of Research}

In order to better know opinions of any group of individuals, in this case teachers from both lower and upper secondary schools in Poland, a survey was applied (data collection type) as one of the research process steps. Subsequent steps of the research process included: selection of topic, analysis and discussion on investigated issue, research project, data collection, data analysis, explication of results as well as submission of information to the teaching community.

We distinguished three phases of conducted research: description, explication, as well as listing of quantitative data (juxtaposition) (Szumski, 1995). As a pre-requisite to the survey questionnaire we studied references for the subject, observed actual school work, analyzed available documents (i.e. survey conducted by members of the Textbook Committee at the Polish Academy of Arts and Sciences), and fully thought through the research issues.

A few fundamental issues were considered during the survey development stage.

1. Would a solution found for the mentioned above issues be useful socially?

2. Will the proposed considerations contribute to improvement of the existing situation?

3. Would those considerations fulfill the social and individual needs (and to what degree)?

4. What will be a practical scope of the research results application? 
It is well known that a conducted research cannot be based on one research technique only. However, while collecting the data from a whole territory of Poland it would be quite cumbersome to travel and conduct interviews, research documentation or observe both students and teachers at work. For this reason the questions included in the survey were structured in various ways. Some of them are closed (with cafeteria or response sets), some open or semi-open. The others consist combination of wording or ideas into pairs; and also associations, comparisons and evaluations, etc. Therefore they are also a form of interview or scale evaluations.

\section{Research Tools}

Survey is one of sociological techniques for collection of data obtained directly by posing questions to selected people who fill in special questionnaires standardized, generally speaking, to a high degree. Its most important features consist of: concrete and single issue questions, imposed selection of one possible response (cafeteria or response set type) in multiple choice layout and possible narrowing of issues (Pilch, 2001).

Any survey may have a diagnostic content, in case of opinion or attitude research, and leads to a detailed registration of particular manifestations of human behaviours. Other surveys may feature exploration structures - a discovery of essential subject characteristics, indication of dependence, but not verification. The second type of research does not require a hypothesis in order to avoid assumed facts and relations. And this was the type of survey, we decided to apply in our research.

Among the other subjects the survey included open questions, where the selection of answer is not imposed upon respondents. Respondents may put their answers in space provided underneath the question. Closed questions were another type of items utilized in the survey. Upon getting acquainted with the content of issue the respondent may choose one (disjunctive question) or a few (conjunctive question) answers from presented selection. There may be a modified alternative question used requesting the respondent to enter „yes“ or „no“ (sometimes also „don't know“). Upper speed of responding and ease of resulting answer analysis by researcher are the merits in these questions. The authors of closed questions are often accused that the respondent may not find an answer consistent with his/her beliefs, then the choice is rather random. This problem was solved by the addition of a specific answer ,other than the above" to cafeteria (or a set of answers) (Zaczynski, 1995).

The survey contained 8 open questions requiring in-depth reflection on the subject, and sometimes impulsive answer based on first association; 4 semi-open questions where one suggested answer could be selected and justified or own answer entered, and 8 closed questions as well as the respondent personal data. It contained $10 \%$ of quantitative questions, and $10 \%$ of qualitative questions.

Questions forming a structure of this survey may be classified into two types: qualitative and quantitative. It is quite important to pose a question in such way that the respondent is able to distinguish requirements pertaining to the answer: should it be a description or an opinion? The presented survey was pertaining mainly to expressing opinions on existing school textbooks, as well as imaginary descriptions of perfect textbooks, therefore the questions were structured accordingly.

It is evident that the number of questions cannot be too high since it might cause a fatigue during responding. It results in loss of integrity, since the respondent renders „any“ answer without any initial consideration. Since the described survey is quite extensive, attempts were made to have it more attractive in order to avoid possible fatigue of 
the respondent while filling in the answers. This was resolved by the use of various commands for answers (such as mark, underline, combine, fill in, enter cross, etc.). The questions were also structured in interesting graphic forms (tables, drawings, textual or symbolic sets of responses, bars, etc.).

\section{Tool Verification}

It is obvious that the survey questions have to be concise, concrete and meaningful as well as comprehensible for the respondents. Language used in the survey must be adjusted to age and education of the respondents. Pilot research was conducted in order to assure that the developed survey meets these requirements. This research included test filling of the questionnaire and subsequent interviews with the respondents. It allowed to determine approximate time of the survey completion. The pilot research confirmed justification of all questions submitted in the survey, however their content was modified in a few cases.

\section{Group of Respondents}

Selection of respondents plays a decisive role in the survey results. In order to receive an answer, one should pose a question to a person able to give such answer (Zaczynski, 1995). Groups within the research group, possible to be distinguished, i.e. chemistry teachers in both lower and upper secondary schools from several towns in various regions of Poland were included in the „questioning“: Gdansk, Szczecin, Poznan, Warszawa, Krakow, Katowice, Rzeszow, Bielsko-Biala, Tarnow, Bochnia, Nowy Targ, Olkusz, Nowy Sacz.

\section{Conducting the survey research - collection of data}

Surveying was conducted in the fall of 2006. A total of 111 surveys were collected. Each of the selected respondents was fully acquainted - with the explanation of the research purpose and treated as a competent partner. The respondents agreed for the research willingly, convinced about the purpose and need for such research and without considering it as a loss of time and nonsense activity.

\section{Result Processing}

The research material (survey results) was duly organized upon collecting. The following criteria were used during the process of this rearrangement: scope of problem; general personal details of respondents (age, length of employment, sex, degree of professional promotion); relations between respondents; type of occurrence (the most important and less important aspects of a given textbook selection, substance, language and graphic analysis of the textbook used in the teaching process, features of a good textbook).

The subsequent step was a codification of data or standardization - that is organization of data with consideration of both content and styling aspects (since the respondent semi-open answers are often quite elaborate). All answers were thoroughly read and general categories of answers established in order to have each partial answer allocated to one category only; such as a selection of textbook used in practical school education, short description of its features, or reasons for change from the textbook used previously.

A common answer sheet (assignment of data into quantitative categories) was developed upon rearrangement of data and its codification. Developed statistics indicate a relationship between the events (and also their intensification, trends and size of the re- 
searched features), as well as help in making comparisons and search for interrelationships between them. This common sheet developed by the authors was presented in the form of Excel worksheet.

A development of the survey statistical approach was initiated by presentation of the research data characteristics in the aspect of demographic and social features (see Table 1).

Table 1. Respondent data sheet.

\begin{tabular}{|c|c|c|c|c|c|c|c|c|c|}
\hline \multirow{2}{*}{$\begin{array}{c}\text { Number } \\
\text { of te- } \\
\text { achers }\end{array}$} & \multicolumn{2}{|c|}{$\operatorname{Sex}(\%)$} & \multicolumn{4}{|c|}{ Age of teachers (\%) } & \multirow{2}{*}{ Kind of school } & \multicolumn{2}{|c|}{$\begin{array}{l}\text { Degree of profes- } \\
\text { sional promotion }\end{array}$} \\
\hline & $\mathrm{F}$ & $\mathrm{M}$ & to 25 & $25-35$ & $35-50$ & $50+$ & & M.Sc. & Ph.D. \\
\hline 60 & 84 & 16 & 16 & 17 & 53 & 14 & $\begin{array}{l}\text { lower secondary } \\
\text { school }\end{array}$ & 52 & 8 \\
\hline 51 & 92 & 8 & 17 & 30 & 28 & 25 & $\begin{array}{l}\text { upper secondary } \\
\text { school }\end{array}$ & 45 & 6 \\
\hline
\end{tabular}

\section{Results and Summing-up}

\section{Textbook among other didactic materials}

Having a choice of four answers (textbook, sets of problems to be solved, exercise books, source texts), majority of teachers at the junior high school level selected - a textbook as necessary aid to work with the students, while at the high school level exercise books appeared to be often chosen next to the textbooks.

\section{Content of textbook}

While analyzing textbook contents, teachers paid the least attention to the bibliography references $(53 \%)$ ). According to the respondents, other unnecessary aspects were as follows: references to internet websites - 47\%, multimedia programs on enclosed data carriers - 47\%, tables with statistical data - 47\%, biographies - $29 \%$, subject $/$ name index $-24 \%$. The teachers prefer other than the table forms of illustration of the statistical data, for example diagrams and graphs showing colourful and crystal clear forms. Emphasis on removal of the index may indicate that the teachers like to see the students to conduct their systematic study - page after page rather than search for some needed facts in the textbook subject index.

\section{Design of textbook}
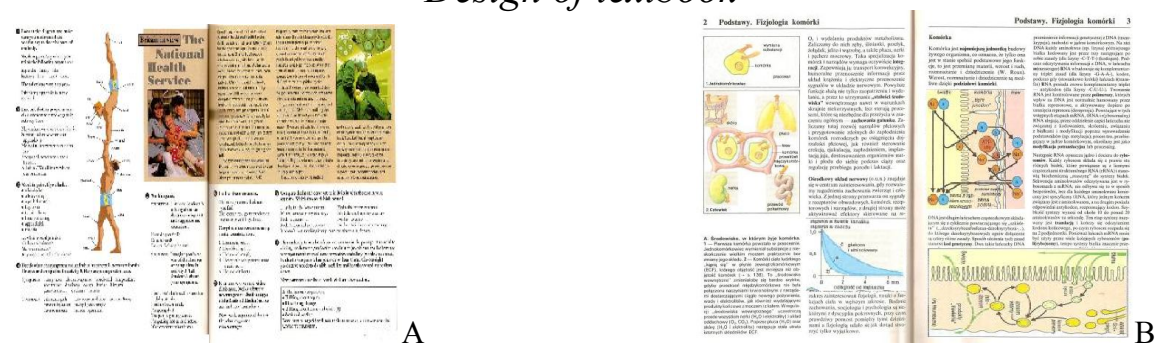

Figure 1. The text and illustration layouts chosen by teachers ( $A$ and $B$ ) 
The responding teachers selected suggestion A as being the most advantageous with respect to the text and illustration layouts for the level of junior high schools (a lot of colour graphics, drawings, pictures and text interweave, various graphic styles are used); while suggestion B was chosen for high school textbooks (diversified sizes and colours of illustration contents). Both pictures and symbols influence the students more effectively at junior high school level, but in case of high schools a structuring of introduced contents becomes more important, and this appeared to be confirmed by the above mentioned choices. In the opinion of teachers, majority of students have a preference to study the textbooks where both text and drawings, showing diversified colours and sizes, interweave with each other. The textbooks with small monochromatic pictures are not popular. A complete separation of text from illustrations (on opposite pages) does not help children in learning the subject.

Notably, $100 \%$ population of respondents would confirm that the wide margins not only do not help the students in their learning process, but on the contrary, interfere with it. In many instances they may almost be construed as a borderline affecting lack of concentration and inability to study! Polish students do not have a habit to make their notes in the margin space (due to instilled appreciation for textbooks and possibility to give them way to subsequent users). This is why they consider those margins to be redundant quite often - thinking it leads to a waste of paper and increase of textbook price.

\section{Methodological aspects of chemistry textbook}

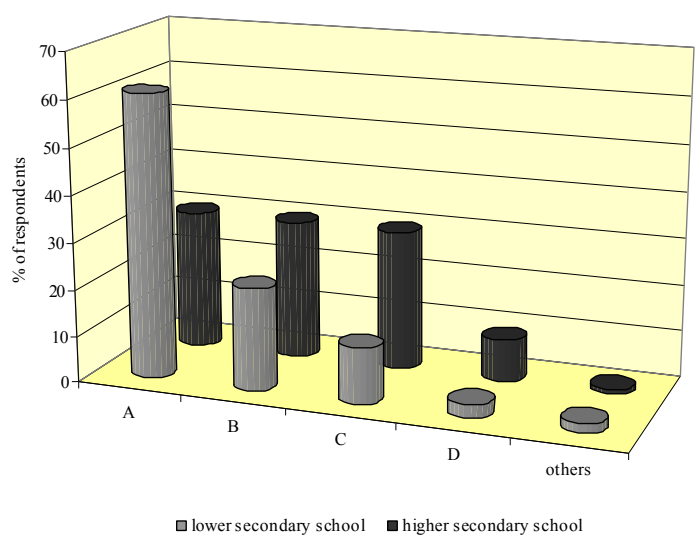

Figure 2. The best chemistry textbooks at lower secondary level and upper secondary level
The figure 2 presents the teachers' opinion regarding to the best chemistry school textbooks used in lower secondary school and upper secondary school, respectively.

$61 \%$ of lower secondary school teachers hold the view that the textbook ' $A$ ' is the best school textbook. It is taken for granted that textbook $\mathrm{C}$ appeared on the market in the last school year; textbook A and textbook $B$ are well known from years.

The selected textbook: 'A' lower secondary school (see figure 2) and 'A1', 'B1', 'C1' - upper secondary school) were submitted for analysis by posing the following questions: Question I.

,Would a currently used textbook allow to:

a) development of positive habits in students; for example self-studying, diligence,

b) student interest in the surrounding world,

c) development of key abilities, i.e. planning and observation,

d) recognition of correct occurrence of phenomena,

e) good perception of cause-and-effect relations,

f) evaluation of effect of human activity on environment,

g) use of information sources, 
h) application of models (experiments) in order to explain phenomena,

i) practical application of knowledge., Handbook A

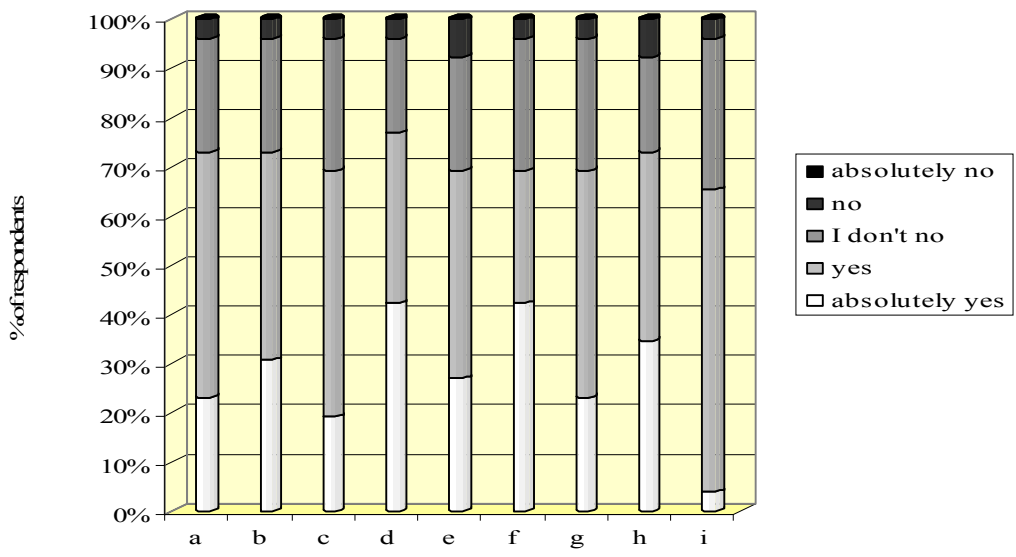

Figure 3. Content analysis of the best chemistry textbook at lower secondary level.

Recognition of correct occurrence of phenomena and evaluation of effect of human activity on environment are the most appreciate features of this textbook. Good perception of cause-and-effect relations and application of models (experiments) in order to explain phenomena are the worst features of this textbook.

Results obtained for the best textbook for upper secondary school 'A1' are similar to those for the best textbook for lower secondary school 'A'. For textbook 'B' (upper secondary school) good perception of cause-and-effect relations and evaluation of effect of human activity on environment are the most appreciate features of this textbook $(67 \%$ of respondents have chosen the answer ,absolutely yes“); use of information sources is the worst feature of this textbook. For textbook ' $\mathrm{C}$ ' development of positive habits in students; for example self-studying, diligence is the most appreciate feature of this textbook ( $67 \%$ of respondents have chosen ,absolutely yes“); development of key abilities, i.e. planning and observation is the worst feature of this textbook.

Question II.

„Would a currently used textbook meet the following criteria:

a) compliance to fundamental curriculum outline,

b) correctness of content,

c) correctness of language,

d) logistic material layout (cause-and-effect),

e) adjustment of used means to the student level of knowledge,

f) consistence of tables, drawings, photographs with text,

g) proper balance of material volumes for each particular topic,

h) compliance with examination requirements,

i) compliance with the current state-of-art,

j) presence of everyday life references,

k) interesting conclusions in each section,

1) presence of interesting facts as well as historical references. , 
Results show that in the case of textbook ' $A$ ' (lower secondary school) compliance to fundamental curriculum outline, correctness of content and correctness of language are the most appreciate features of this textbook ( $81 \%$ of respondents have chosen ,absolutely yes").

For the textbook 'A1' (upper secondary school) compliance to fundamental curriculum outline, compliance with examination requirements and compliance with the current state-of-art are the most appreciate features of this textbook; presence of interesting facts as well as historical references is the worst feature of this textbook. For textbook 'B1' (upper secondary school) compliance to fundamental curriculum outline, correctness of content and compliance with examination requirements are the most appreciate features of this textbook; adjustment of used means to the student level of knowledge, consistence of tables, drawings, photographs with text and interesting conclusions in each section are the worst features of this textbook. For textbook ' $\mathrm{C} 1$ ' compliance to fundamental curriculum outline is the most appreciate feature of this textbook; interesting conclusions in each section is the worst feature of this textbook.

While analyzing teacher responses, it was possible to note the following inputs:

- the teachers wish to replace the present textbook, since some of chemical topics were not updated in the one currently used (regardless of the issued revisions), also its scope is not commensurate with examination requirements and language was found to be difficult for students. Furthermore, the textbook is „overloaded“ with topic contents, heavy and in case of the high school textbook - some content is just repeated from the junior high textbook and show too many generalizations

- while a new textbooks feature: low price, compliance with current state-of-art, are included in the educational package together with the lesson scenarios, also include educational curriculum, sets of problems for resolving, exercise books, multimedia programs, and they also cover all 3 years of the junior high syllabus.

The teachers have noticed that the following trends may be seen in the textbooks available from the book market:

- a tendency of failing to provide pure facts, dates and notions to the readers

- exclusively from the scope of the programme base, towards teaching of how to use them,

- the provision of a lot of interesting information, references to the everyday life

- and explanations based upon the social events, etc., in the contents of the textbooks,

- the textbooks contain photographs and illustrations without making reference to the text,

- the experiments are described improperly and conclusions are erroneous;

- some information is irrelevant,

- the textbooks contain long-term and time-consuming testing,

- the textbooks contain a lot of jargon expressions, grammar irregularities, nonunderstandable sentences,

- chemical material mistakes,

- the textbooks, as well as cycles thereof, are characteristic of the prevalent, author specific methods of guiding the reader (inductive method, deductive method, etc.).

The users paid the attention to the significance of the graphic patterns (the role of drawings, photographs, distribution of the contents and the layout of illustrations on the 
pages, fonts and font sizes used, additional symbols, etc.). According to the teachers surveyed, some textbooks have nothing in common with a high level of chemistry thinking, a high study motivation, inspiring students for further study, social significance, upper order categories characterized by knowledge structures assuming application knowledge.

\section{Note}

Paper has been presented in the framework of the IOSTE Conference, Hammamet (Tunisia), 7 - 10 February 2007.

\section{References}

Bakonis, E. (1998). Analysis of textbooks: theory and practice. VTIC - Newsletter/Textbook research and Information Centre for the Baltic Countries (VTIC). Vilnius, 1, p. $8-9$.

Koulaidis, V. (2004). Towards a Framework of School Textbooks' Analysis. $7^{\text {th }}$ European Conference on Research in Chemical Education. Programme and Abstracts. Ljubljana, Slovenia, p.32-33.

Lobocki, M. (1999). Wprowadzenie do metodologii badań pedagogicznych. Kraków: Oficyna Wydawnicza Impuls.

Pilch, T., \& Bauman, T. (2001). Zasady badań pedagogicznych. Strategie ilościowe i jakościowe. Warszawa: Wydawnictwo Akademickie „Żak“.

Pingel, F. (1999). UNESCO Guidebook on Textbook Research and Textbook Revision. Hannover, Verlag Hahnsche Buchhandlung, (pp.9-11).

Skrzypczak, J. (2003). Podręcznik szkolny. Wymagania, ocena, rozbudowa, metodyka stosowania. Poznań: Wydawnictwo eMPi ${ }^{2}$.

Szumski, G. (1995). Dobór i ksztatcenie uczniów zdolnych. Warszawa: WSPS.

Weinbrenner, P. (1992). 'Methodologies of Textbook Analysis used to date', in Bourdillon, H. History and Social Studies - Methodologies of Textbook Analysis, Amsterdam, Swets and Zeitlinger.

Zaczyński, Z. (1995). Praca badawcza nauczyciela. Warszawa: WSiP.

Received 12 December 2010; accepted 25 March 2011

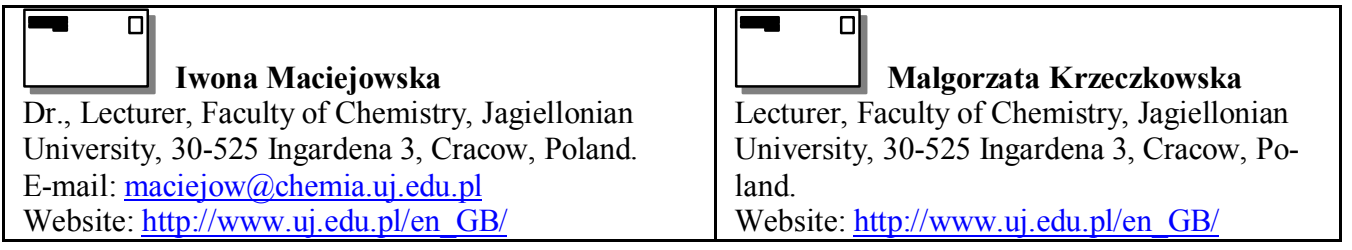

